\title{
Commentary: Remote learning creates more room at the table
}

\author{
Hope A. Feldman, MD, and \\ Mara B. Antonoff, MD, FACS
}

It is difficult to think of an area of daily life that has not been impacted by the novel coronavirus disease 2019 (COVID19) pandemic. Still harder is recognizing a silver lining during a time that has been devastating for so many people. In this Expert Opinion, Vervoot and colleagues ${ }^{1}$ discuss the many benefits to be gained from the increased use of online platforms for surgical education and conferences.

Continuing surgical education during this unprecedented time-a time in which maintaining an adequate physical distance from others has been prioritized-has posed a number of new challenges. In place of grand rounds held in large auditoriums, one now finds resident and attending physicians sitting attentively in front of computer screens. All conferences have been cancelled or moved to online platforms for the foreseeable future. The settings have changed, yet the learning has continued. Many residency and fellowship programs have quickly integrated novel virtual learning platforms into their curricula. ${ }^{2-4}$ Some have argued that our current experiences have allowed for reassessment of prior teaching methods, ultimately resulting in improvements that will outlast the pandemic. ${ }^{5}$ While these changes have certainly come with some growing pains, Vervoot and his colleagues ${ }^{1}$ have concluded that there should be a role for continued use of these technologies in the future.

In their article in this issue of the Journal, Vervoot and colleagues illustrate the many benefits of remote learning. They discuss the massive attendance at this year's American Association for Thoracic Surgery virtual conference, and they highlight the ability of this new platform to allow

\footnotetext{
From the Department of Thoracic and Cardiovascular Surgery, University of Texas MD Anderson Cancer Center, Houston, Tex.

Disclosures: The authors reported no conflicts of interest.

The Journal policy requires editors and reviewers to disclose conflicts of interest and to decline handling or reviewing manuscripts for which they may have a conflict of interest. The editors and reviewers of this article have no conflicts of interest.

Received for publication Aug 3, 2020; revisions received Aug 3, 2020; accepted for publication Aug 3, 2020; available ahead of print Aug 6, 2020.

Address for reprints: Mara B. Antonoff, MD, FACS, Department of Thoracic and Cardiovascular Surgery, University of Texas MD Anderson Cancer Center, 1515 Holcombe Blvd, Houston, TX 77030 (E-mail: MBAntonoff@mdanderson.org).

J Thorac Cardiovasc Surg 2021;161:758-9

$0022-5223 / \$ 36.00$

Copyright (c) 2020 by The American Association for Thoracic Surgery

https://doi.org/10.1016/j.jtcvs.2020.08.002
}

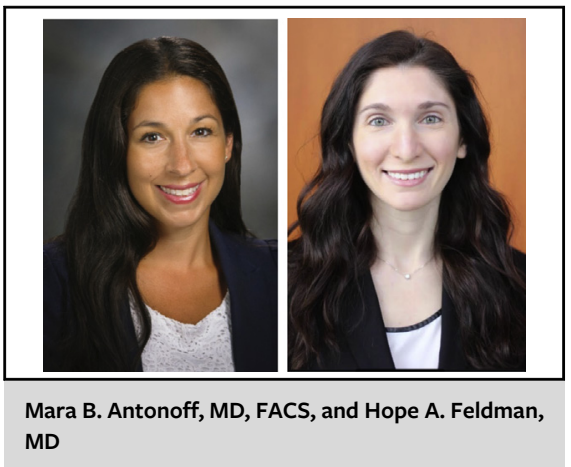

CENTRAL MESSAGE

The COVID-19 pandemic has necessitated changes in surgical education. The online platforms that replaced in-person gatherings have allowed for increased participation from a diverse audience.

individuals who may not have previously had the time or means to travel to conferences to participate. The online format has created an open door for individuals who may be geographically disparate, inviting a global community of surgeons to connect and collaborate. Moreover, for individuals who may lack funding or experience challenges in getting time away from clinical or personal obligations, opportunities now abound. Even outside of a pandemic, travel may be challenging for trainees and early careerists trying to balance child-bearing and child-rearing with academic careers. ${ }^{6}$ Now, more than ever, as we think about the face of cardiothoracic surgery and broadening our efforts toward diversity and inclusivity, it's critical to ensure that we are making seats at the table for all. ${ }^{7}$ One of the unexpected benefits of the virtual venue is that, not only does it create opportunity for more participants to hear from the experts, it creates a more welcoming means of allowing all participants to interact with the so-called experts. We know that women and underrepresented minorities may be reluctant to speak up or ask questions in a live format, and the virtual format allows anyone with a thoughtful, articulate question the opportunity to pose it-without the social and political stressors of waiting in line at the podium. ${ }^{8}$

Aldous Huxley, the author of the referenced Brave New World, wrote, "I wanted to change the world. But I have 
found that the only thing one can be sure of changing is oneself." We are currently living in a time in which much of what goes on around us is beyond our control. However, as a surgical community, we must adapt to the current circumstances order to continue advancing our field, training future generations, and providing the best possible care to our patients.

\section{References}

1. Vervoot D, Dearani JA, Starnes V, Thourani V, Nguyen T. Brave New World: virtual conferencing and surgical education in the Coronavirus Disease 2019 era. J Thorac Cardiovasc Surg. 2021;161:748-52.

2. Almarzooq ZI, Lopes M, Kochar A. Virtual learning during the COVID-19 pandemic: a disruptive technology in graduate medical education. J Am Coll Cardiol. 2020;75:2635-8.
3. Chick RC, Clifton GT, Peace KM, Propper BW, Hale DF, Alseidi AA, et al. Using technology to maintain the education of residents during the COVID-19 pandemic. J Surg Educ. 2020;77:729-32.

4. Lewis EE, Taylor LJ, Hermsen JL, McCarthy DP, Fiedler AG. Cardiothoracic education in the time of COVID-19: how I teach it. Ann Thorac Surg. 2020;110: $362-3$.

5. Fuller S, Vaporciyan A, Dearani JA, Stulak JM, Romano JC. COVID-19 disruption in cardiothoracic surgical training: an opportunity to enhance education. Ann Thorac Surg. June 1, 2020 [Epub ahead of print].

6. Antonoff MB. Opportunities for academic achievement during parental leave: the Society of Thoracic Surgeons sets the standard. Ann Thorac Surg. 2018;106: 321-3.

7. Cooke DT, Olive J, Godoy L, Preventza O, Mathisen DJ, Prager RL. The importance of a diverse specialty: introducing the STS workforce on diversity and inclusion. Ann Thorac Surg. 2019;108:1000-5.

8. Antonoff MB, Stephens EH, Blackmon SH. Meeting the educational needs of an increasingly diverse surgical workforce. JAMA Surg. 2020;155:533-4.

9. Huxley A, Huxley A. Point Counter Point. London: Chatto \& Windus; 1928. 